\title{
A ESPHINGE: REFLEXÕES EM TORNO DO GÊNERO FICÇÃO CIENTÍFICA NO INÍCIO DO SÉCULO XX
}

\section{THE ESPHINGE: REFLECTIONS AROUND GENDER SCIENCE IN THE EARLY 20th CENTURY}

\author{
Auriane Leal Santos ${ }^{1}$ \\ Naiara Sales Araújo ${ }^{2}$
}

Recebido em: 22 ago. 2019

Aceito em: 17 dez. 2019

\begin{abstract}
RESUMO: O objetivo desse artigo é fazer uma reflexão acerca do gênero ficção científica e sua relação com o conhecimento não científico, no início do século $\mathrm{XX}$, a partir da obra $A$ Esphinge (1920) de Coelho Neto, focando nos aspectos sociais da época. Durante muito tempo, as obras de ficção científica se confundiram com narrativas fantásticas e góticas pelo caráter híbrido típico das narrativas especulativas. Muitas obras brasileiras do final do século XIX e início do século XX, buscaram nas crenças e misticismo uma forma de explicitar as incertezas e contradições advindas com os avanços tecnológicos. Nesta perspectiva, como suporte teórico, traremos à baila os estudos sobre ficção científica realizados por Elizabeth Ginway, Roberto de Sousa Causo, Alexander Silva, dentre outros.
\end{abstract}

Palavras-chave: Ficção Científica. Sociedade. Coelho Neto. Literatura.

ABSTRACT: This study aims to reflect on the genre of science fiction and its relationship with non-scientific knowledge in the early 20th century, based on Coelho Neto 's A Esphinge (1920), focusing on the social aspects of this time. For a long time, Science Fiction works have been confused with fantastic and gothic narratives for its hybrid character typical of speculative narratives. In Brazil, some works from the last decades of the 19th century and early 20th century, sought in the beliefs and mysticism ways to explain the uncertainties and contradictions arising from technological advances. In this perspective, as a theoretical support, one brings to

\footnotetext{
1 Tem experiência na área de Comunicação, com ênfase em Comunicação Visual. Atualmente, estuda na Universidade Federal do Maranhão (UFMA) cursando Letras com habilitação em Inglês; Participa dos grupos de pesquisa nas linhas da Literatura Maranhense, Ficção Científica. E-mail: aurianelealsantos@ @otmail.com

${ }^{2}$ Possui Licenciatura Plena em Letras Inglês pela Universidade Federal do Piauí (2001), Mestrado Acadêmico em Letras pela Universidade Federal do Piauí (2007), mestrado em Estudos Literários pela Universidade Metropolitana de Londres (2008) e Doutorado em Literatura Comparada pela Universidade Metropolitana de Londres (2013) e Pós-doutorado pela Universidade de Granada. Atualmente é professora da Universidade Federal do Maranhão onde é professora do mestrado acadêmico em Letras e professora de Língua e Literatura Inglesa na graduação. É líder do Grupo de Pesquisa FICÇA (Ficção Científica, Gêneros Pós-Modernos e Representação Artísticas na Era Digital), Líder do Grupo de Pesquisa GEPELA (Grupo de Estudos e Pesquisas em Linguística Aplicada), coordenadora do Projeto de pesquisa Ficção Científica e Sociedade (UFMA) e dos projetos de extensão Línguas e Cultura do Maranhão e Cursos de Línguas Estrangeiras. E-mail: naiara.sas@gmail.com
} 
discussion contributions by Elizabeth Ginway, Roberto de Sousa Causo, Alexander Silva, among others.

Keywords: Science Fiction. Society. Coelho Neto. Literature.

\section{INTRODUÇÃO}

A Ficção Científica (FC) tem se tornado popular ao longo dos anos gerando frequentes discussões em torno de sua definição. Muitos estudiosos a limitam apontando apenas para seu caráter futurístico e especulativo. No entanto, é possível constatar que em muitas obras, esse tipo de narrativa discute e reflete sobre os problemas atuais além de prever as consequências da ação do homem sobre o meio social.

Em O que é Ficção Científica? (1992, p. 25), o brasileiro Bráulio Tavares evidencia "que o objetivo da FC não é prever o futuro [...]. Mesmo assim existem casos de profecias da FC que acabam se realizando tempos depois", corroborando a ideia de que a FC é uma literatura que pode prenunciar o porvir, e por isso está à frente de seu tempo.

Outro teórico brasileiro que contribui com esta discussão é André Carneiro. Em seu livro Introdução ao Estudo da Science Fiction (1968), Carneiro afirma que é a partir do modo como os autores encaram e julgam as coisas que as suas obras são construídas, o que os faz projetar medos, anseios, incertezas, sonhos e idealizações. No Brasil, embora possamos citar exemplos do início do século XX, a FC começou a se destacar e popularizar na década de 60, ainda que alguns autores associassem a produção desse gênero a países tecnologicamente desenvolvidos.

De acordo com Roberto Causo, na sua obra Ficção científica, fantasia e horror no Brasil 1875 a 1950 (2003, p. 21), a produção de obras da FC era rara devido à associação do Brasil como pertencente ao bloco de países de terceiro mundo pois o país continuou sendo um país agrarista e escravista durante muito tempo. Mesmo após a sua independência política, a agenda literária brasileira girava em torno das narrativas nacionalistas e/ou regionalistas.

Ainda segundo Causo (2003), foi no início do século XX que muitos projetos políticos voltados para a organização do trabalho passaram a aplicar as ideologias eugenistas, racistas, tayloristas e fordistas nos grandes centros urbanos possibilitando aos escritores um olhar mais 
crítico sobre as novas tendências e estilo de vida que os brasileiros deveriam adotar para acompanhar os avanços tecno-científicos.

No início do século $\mathrm{XX}$ num momento em que vários projetos políticos de controle das populações proletárias de negros e imigrantes aplicam ideologias eugenistas, racistas, tayloristas e fordistas à organização nacional do trabalho em centros urbanos como Rio de Janeiro e São Paulo, a ficção [...] imagina o futuro do Brasil (CAUSO, 2003, p. 22).

Esse contexto de incerteza frente ao processo de modernização foi o cenário da grande maioria das produções nesse período. Atentos à forma como estes avanços impactariam nos hábitos e costumes dos brasileiros, alguns escritores voltaram seus olhares para aquilo que parecia ser a maior riqueza de um povo: a identidade e os elementos que a compõem.

No Maranhão, esta realidade não foi diferente. Alguns escritores, apesar de não serem tão reconhecidos por este tipo de narrativa, registraram suas impressões em obras que podem ser caracterizadas como pertencentes ao gênero de FC: Coelho Neto, em A Esphinge (1908), objeto de estudo desta pesquisa, Humberto de Campos em Os olhos que comiam carne e Morfina (1932), dentre outros.

A Esphinge, de Coelho Neto, foi publicada em 1908 e aborda temas intrigantes como a vida construída em laboratório, inteligência artificial e até a androgenia. A narrativa se passa na cidade do Rio de Janeiro, capital da República. Os fatos que norteiam o enredo giram em torno da aproximação do narrador, tradutor contratado pelo excêntrico inglês, James Marian, para traduzir o livro de sua vida, ambos hospedados na pensão da proprietária inglesa, Miss Barkley.

No decorrer da trama, o narrador descobre que James Marian é fruto de um experimento científico realizado pelo místico oriental Arhat, que utilizara os conhecimentos da "Magna Ciência" para dar vida a dois corpos mutilados, fundindo o corpo do irmão à cabeça da irmã. A vida do inglês sempre estivera envolta em mistério ou misticismo, seja pela sua aparência, seja pelo seu envolvimento com algumas situações inexplicáveis associadas à morte da personagem Miss Fanny, com quem o andrógino se relacionara.

Dessa forma, o presente artigo tem como principal objetivo analisar A Esphinge (1908) a fim de ressaltar as características da FC brasileira e sua ligação com a sociedade do final do século XIX e início do XX. Para isso propõe-se um estudo sobre o contexto histórico em que a 
obra está inserida, bem como sobre a trajetória e as características desse gênero no Brasil ressaltando sua ligação com crenças ou misticismos.

\section{BRASIL DO FINAL DO SÉCULO XIX E INÍCIO DO XX}

Historicamente, o final do século XIX e início do século XX foram marcados pelo surgimento de diferentes correntes de pensamento que contestavam o modelo capitalista de produção e apontavam para formas mais igualitárias de meios de produção e distribuição de bens e riquezas. A eminente consolidação do progresso científico e tecnológico favoreceu importantes avanços na área da medicina e da química, como a descoberta dos antibióticos e das vacinas, bem como uma mudança brusca nos meios de comunicação.

O período que antecede a Primeira Guerra Mundial, também conhecido como Belle Époque (1871-1914), foi um período de otimismo e produtividade, em que a Europa obteve uma rápida expansão e progresso no âmbito tecnológico, científico e cultural, como aponta o crítico Alexandres Meireles da Silva (2008):

A Belle Époque europeia foi a culminância de um processo de fins do século
XIX e início do século XX caracterizado de um lado pela prosperidade
econômica resultante da industrialização rápida e da exploração colonialista,
advindas ambas da hegemonia do racionalismo científico, e de outro pela
estabilidade política, derivada de uma teia complexa de alianças diplomáticas,
e reforçada em muitos casos por laços de sangue ou casamento (SILVA, 2008,
p. 80).

Essa rápida industrialização e prosperidade econômica foram responsáveis por grandes avanços tecnológicos e, consequentemente, mudanças no modo e estilo de vida das pessoas, gerados em parte pelo processo de modernização dos centros urbanos e expansão do mercado capitalista. No entanto, na contramão do progresso, havia uma insatisfação das classes populares pois as precárias condições de vida dos operários, e sobretudo das crianças, eram ainda realidades que deveriam ser enfrentadas.

Nesta época, o Brasil passou por várias mudanças, especialmente a cidade do Rio de Janeiro, que buscava afastar-se das características coloniais para alcançar o desenvolvimento que a República tentava proporcionar. Segundo aponta Silva (2008):

A cidade do Rio estava determinada a abandonar o estilo de vida colonial, que ainda marcava o seu cotidiano, em favor de uma metrópole nova, moderna, européia, voltada para o novo século e moldada pela égide da ciência e do progresso (SILVA, 2008, p. 82). 
Essa modernização afetou a vida cultural e também toda a organização social da cidade que buscava afastar-se do colonialismo para alcançar o progresso europeu. De acordo com Nicolau Sevcenko em seu livro Literatura como Missão: tensões sociais e culturais da Primeira República (1995):

[...] acompanhar o progresso significava somente uma coisa: alinhar-se com os padrões e o ritmo de desdobramentos da economia européia, onde 'nas indústrias e no comércio o progresso do século foi assombroso, e a rapidez desse progresso miraculosa (SEVCENKO, 1995, p. 29).

Em outras palavras, o modelo europeu era um alvo a ser atingido, associando a isso os avanços tecnológicos dele decorridos. O slogan "O Rio Civiliza-se" difundido pelo Gazeta de Notícias durante o mandato do prefeito Pereira Passos e do presidente Campos Sales, propagava as mudanças significativas que aconteciam na cidade e também as campanhas contra a peste bubônica, a febre amarela e a varíola.

Ainda segundo Sevcenko (1995, p. 30) O Rio de Janeiro estava passando por uma transformação radical em que a velha cidade feia e suja seria reestruturada para se equiparar ao padrão europeu e desenvolver-se economicamente. Foi nesse período também que foram destruídos os cortiços - conhecidos como centros de proliferação de doenças e sujeiras abrindo assim, espaço para a construção de favelas às margens da cidade carioca.

Dentre as principais mudanças que a modernização proporcionou, pode-se destacar que as atividades de exportação passaram a focar nos cafezais dos grandes centros urbanos como São Paulo e Rio de Janeiro, houve também a inauguração da Avenida Central e da Avenida Beira-Mar na capital da República e a promulgação da lei que obrigava a vacinação a fim de combater as doenças como a febre amarela e a varíola.

Apesar de se explorarem uma realidade nacional, as obras desse período, como afirma Alexandres Meireles (2008, p. 11) "refletem a influência das ideias europeias, e em especial francesas e britânicas, sobre a sociedade carioca da época nas esferas sociais, científicas e artísticas”. Desse modo, a literatura da Belle Époque reproduz - principalmente - as características europeias, francesas e britânicas, em relação aos aspectos sociais, científicos ou artísticos. 
Nesta perspectiva, a FC brasileira debruçou-se sobre as transformações sociais do final do século XIX e início do século XX, com suas obras influenciadas pela Revolução Científica, como aponta Meireles (2008, p. 06). A sociedade carioca mergulhava em um misto de fascinação e terror, que por vezes, refletia o misticismo em relação ao progresso e à ciência. Isso se refletiu na literatura desse período, como pode ser percebido na obra A Esfinge, de Coelho Neto.

\section{A FICÇÃO CIENTÍFICA EM A ESPHINGE DE COELHO NETO}

Como apontado anteriormente, o enredo de A Esphinge (1908) se passa na cidade do Rio de Janeiro na pensão da inglesa Miss Barkley. A trama se desenvolve em torno do personagem James Mariam e sua aproximação com um dos hospedes (e também narrador do livro).

O protagonista é uma figura reclusa e excêntrica que possui a cabeça de mulher e o corpo de homem devido à uma experiência da Magna Ciência ${ }^{3}$. A narrativa de $A$ Esphinge, remete à obra Frankenstein (1818), de Mary Shelley, considerada por muitos críticos como a primeira obra de Ficção Científica, na qual o cientista Victor Frankenstein dá vida a uma criatura horrenda feita a partir de membros retirados de diferentes copos sepultados.

De acordo com Roberto de Sousa Causo (2003, p. 115), o dilema de James não é a rejeição de seu criador, mas a sua sexualidade dividida, e essa duplicidade do personagem já é anunciada a partir do seu nome, o primeiro (James) remete ao masculino e o segundo (Mariam), ao feminino. A respeito dessa androgenia presente na figura do protagonista, Sônia Sebastião afirma na obra Sujeito pós-moderno: de andrógino ao pós-humano (2010)

Na figura do andrógino, a função sexual é omissa, representando a inocência primordial e acultural pela inexistência de papéis ou estereótipos sociais. A predominância social da mulher ou do homem varia, consequentemente, de povo para povo, de tradição para tradição, sendo possível encontrar sociedades primitivas em que não existe a preponderância de nenhum dos géneros.

\footnotetext{
${ }^{3}$ Também conhecida como Magia Branca, a Magna Ciência é a arte de aprender a pensar e aprender a conhecer os mecanismos da mente, as energias emanadas pelos pensamentos e seus efeitos. É aprender a definir o bem e o mal e o utilizar-se do conhecimento para melhor viver. <html:joaquimfreixomundosparalelos.blogspot.com/2012/08/magna-ciencia-ou-magia-branca>
} 
Portanto, a figura do andrógino elimina (ou antecede) o estereótipo do género (SEBASTIÃO, 2010, p. 62).

O drama do protagonista se resume na busca de seu destino e até da sua sexualidade, justamente por não se encaixar nos estereótipos sociais, apesar de se fixar na identidade feminina ao logo de sua trajetória. Isso pode ser constatado por meio da fala do personagem Arhat:

Se em ti predominar o feminino, que transluz na belleza do teu rosto, o rosto de tua irman, serás um monstro; se vencer o espírito do homem, como faz acreditar o vigor dos teus músculos, serás como um iman de lascívia. Mas infeliz serás, como ainda não houve outro no mundo se as duas almas que pairavam sobre a carne rediviva lograrem insinuar-se nella (NETO, 1920, p. 173).

O personagem ainda não tem uma identidade definida, e por isso as duas almas se dividiam no mesmo corpo, pois se predominasse o feminino ele transparecia em seu rosto a beleza feminina, mas se fosse o contrário, ele estaria submetido apenas ao prazer sexual, sem limites. Tem-se aqui o resultado de uma experiência da Magna Ciência realizada pelo austríaco Arhat, o corpo do menino - cuja cabeça foi decapitada - e a cabeça da menina foram unidos para darem vida a James Mariam:

Valendo-me das noções que possuo da Magna Sciencia, como ainda encontrasse vestigios, ou melhor: manifestações da presença dos sete principios, retive a força de jiva, ou principio vital [...] aproveitei dos corpos que não fôra attingido. Tomando a cabeça da menina e adaptando-a ao corpo do menino restabeleci a conexão, reavivei os fluidos e assim [...] refiz uma vida, em um corpo de homem, que é tu (NETO, 1920, p. 167-168).

Trazer os conhecimentos da Ciência Magna ilustra a ideia de que os conhecimentos científicos se misturam aos conhecimentos não explicados pela ciência, ou seja, conhecimento que beira o sobrenatural ou desconhecido. Para Bráulio Tavares (1992, p. 17), a ciência é o triunfo do conhecido sobre o desconhecido, e os elementos científicos presentes na narrativa, embora tenham sido primitivos se comparados aos parâmetros atuais, explicavam os acontecimentos sobrenaturais que permearam a vida do protagonista. Nesse sentido, Causo (2003, p. 113) destaca que a ciência presente na obra de Coelho Neto é envolta do misticismo 
oriental reencarnacionista, que juntamente com os elementos simbolistas e espíritas refletem o cenário do Brasil nessa época.

Nessa discussão, Alexander Meireles (2005, p. 36) afirma que o interesse pela ciência fez com que alguns autores construíssem as suas narrativas com elementos científicos associando-os às reflexões sobre a influência destes neste cenário. Autores como Monteiro Lobato e sua obra O Presidente Negro (1925) e Gastão Cruls com o livro Amazônia Misteriosa (1925) trazem esses aspectos em seus livros e o trecho acima corrobora o pensamento de Silva já que a ciência faz parte de toda a estrutura da narrativa de Coelho Neto, pois é em torno da vida de James que a obra foi construída.

Bráulio Tavares (1992, p. 61) declara que "As primeiras tentativas da FC em imaginar 'criaturas artificiais' seguiram o caminho mais previsível: o da criatura fabricada em laboratório, à nossa imagem e semelhança". E como mencionado anteriormente, a obra de Frankenstein (1818) da autora Mary Shelley é considerada por muitos críticos como a primeira a abordar essa vertente da criação artificial e na obra de Coelho Neto, isso se evidencia quando Arhat traz à vida o andrógino James, mesmo que por meio da Ciência Magna.

Discussões em torno do progresso científico eram constantes no meio intelectual da elite brasileira. A obra de Coelho Neto é permeada por essas discussões, o que pode ser percebido pelo trecho abaixo, quando um dos hóspedes declara sua insatisfação com as ilusões do "progresso", pois este se reservava apenas às classes mais altas da sociedade, mascarando as misérias que atingia a maior parte dos habitantes da cidade:

Meu caro, a Sciencia é uma columna em espiral gyrando sempre. Parece-nos que as espiras avançam investindo com a altura...infelizmente isso não passa de illusão, pura illusão, não é verdade? Chegamos até a cornija do Templo, d'ahi para cima é o grande vácuo e as espiras verrumam, verrumam...Falamos em progresso e rolamos na morte. Nada se sabe (NETO, 1920, p. 122-123).

É a partir dessa passagem que se nota o desencanto de alguns personagens com as consequências dos avanços científicos, pois apesar de estarem em constante processo de transformação, as classes mais baixas continuavam marginalizadas e sofrendo pela falta de estrutura mínima de saneamento básico, assistência à saúde e moradia, dentre outros fatores. Elizabeth Ginway (2005) reitera que: 
A ficção científica brasileira demonstra uma desconfiança básica da ciência e da tecnologia na mão dos humanos [...]. Além disso, por causa de uma aguda divisão de classes na sociedade brasileira e da concentração de poder de poder e dinheiro entre a elite tradicional, a tecnologia é vista como um elemento divisor, ao invés de unificador. Para os brasileiros, ciência e tecnologia parecem se somar aos problemas políticos e econômicos ao invés de resolve-los (GINWAY, 2005, p. 39).

Essa reflexão que Coelho Neto expõe o desencanto científico e é corroborada com o trecho acima de Elizabeth Ginway, do livro Ficção Científica Brasileira: Mitos Culturais e Nacionalidade no País do Futuro (2005), em que a autora afirma que isso ocorre devido o brasileiro não confiar na tecnologia e na ciência por estarem em mãos humanas, além destas serem um divisor entre a elite cultural e o proletariado, as mesmas podem ainda se somarem aos problemas políticos e econômicos já existentes ao invés de ajudar em suas resoluções, é perceptível que essa visão possa ser resultado de fatores culturais e históricos.

O fato de o personagem principal ter vivido em uma habitação isolada dos centros urbanos e só ter saído da casa após a morte de Arhat, explicaria também a sua reação de descontentamento frente à industrialização. Como desabafo, James Mariam reitera a ideia de desumanização em prol do progresso:

Visitei fábricas e oficinas, e comovi-me diante dos engenhos desumanos que, assim como o arado, revolvendo, sulcando a terra, mata as ervas humildes para que a seara do pão cresça sem parasitas, assim vão eles desalojando os fracos em benefício dos fortes. Tudo vi (NETO, 1920, p. 179).

Vê-se que Coelho Neto traz à baila discussões pertinentes que dialogam com uma sociedade que vivia à beira do desconhecido e incerto, proporcionados pelos avanços tecnológicos. Elizabeth Ginway (2005, p. 24) ilustra que boa parte da população sofreu com o aumento da subnutrição e da pobreza, ou seja, não experimentaram os efeitos benéficos do processo de modernização, conforme Coelho Neto retrata no trecho acima sobre a situação desumana que os pobres eram submetidos nas fábricas e oficinas.

Ginway (2005, p. 42) também afirma que a FC do séc. XX reflete o sentimento de que a modernização é uma repetição da experiência colonial, ou seja, mesmo com a implantação de 
novas tecnologias e a expansão da indústria, o Brasil ainda possuía raízes coloniais no ambiente industrial. O protagonista de Esphinge ratifica as péssimas condições que os trabalhadores assalariados eram submetidos e que propiciou a rápida expansão econômica, submetendo os mais fracos em benefício dos mais fortes. Ainda em relação às consequências dessa "modernização" no que se refere aos trabalhadores fabris, James destaca que:

\begin{abstract}
Saímos dos squares opulentos e chafurdávamos nas vielas nojosas onde vermina um povo lúgubre, espectral, doloroso: homens, mulheres, crianças arrepanhando farrapos imundos à nudez macilenta, estendendo a mão descarnada, cercando-nos, a arrotar pedidos, investindo com feição sinistra ou rastejando, a chorar. Seres hediondos que desbordavam das baiucas lobregas, uns esquálidos, tiritando de febre, outros dum roxo apoplética [...] crianças que não conheceram a inocência [...] fugíamos acossados pelos maltrapilhos e, em breve, emergíamos no esplendor da cidade (NETO, 1920, p. 180-181).
\end{abstract}

Ginway (2005, p. 25) também afirma que "a despeito dos esforços de modernizar sua economia, a sociedade brasileira ainda sofre com muitos dos urgentes problemas sociais que a modernização buscava reparar" e isto é perceptível no romance de Coelho Neto devido a tristeza de James com a realidade de trabalhadores das manufaturas e também com a pobreza evidenciada nas ruas por homens, mulheres e crianças maltrapilhas que ocupavam as vielas da cidade. Nesse contexto, a obra buscava retratar a realidade social, que a República tentava "mascarar".

Durante a Belle Époque, alguns escritores se apropriavam da miséria humana, da violência e do crime para ambientarem suas narrativas, especialmente, nos grandes centros urbanos, como confirma Coelho Neto (1920, p. 181-182) "E no square os carros passavam por entre alas de miseráveis que esmolam, corriam com a pureza ao vicio ou espreitavam o momento oportuno do furto ou o assalto violento, à mão armada, na sombra". Pode-se destacar que as pessoas das classes mais baixas viviam à margem da sociedade, na espreita dos becos cariocas, em condições desumanas.

O fato do protagonista identificar essas desigualdades sociais somente após a morte do cientista Arhat ilustra a ideia de que a ciências consegue gerar uma realidade fantasiosa e/ou ilusória capaz de gerar expectativas que podem resultar em frustrações ou desilusões. A morte 
do cientista dá a James Marian a possibilidade de descobrir sua própria verdade e experienciar uma realidade que até então desconhecida por ele.

De acordo com Antonio Candido em seu livro A personagem do Romance (2007, p. 53) ao se pensar no personagem de uma obra, direciona-se o pensamento à vida que eles vivem, nos problemas que o cercam e as ideias que estes expressam. Coelho Neto reflete - em sua obra - a elite cultural da Belle Époque, pois residia na pensão um professor de piano Frederic Brandt, o comendador Bernaz, a professora inglesa Miss Fanny, dois estudantes de Medicina Décio e Alfredo Penalva, um estudante de Direito Chrispin, além de James e o narrador (cuja identidade não é revelada).

O desfecho da obra se dá com a descoberta do narrador acerca do mistério que envolve a vida de James e a partida misteriosa do protagonista no navio chamado Avon, finaliza-se também a jornada do protagonista em relação a sua origem, pois que a mesma já foi desvendada pelo narrador. Coelho Neto construiu uma narrativa que envolve mistério e também as mudanças e avanços científicos que os séculos XIX e XX proporcionaram na capital da República, bem como os seus impactos na vida das pessoas.

\section{CONSIDERAÇÕES FINAIS}

A Belle Époque foi um período de grandes transformações sociais, políticas e ideológicas. A cidade do Rio de Janeiro, durante o governo do presidente Campos Sales (18981902) e do Prefeito Pereira Passos (1836-1913), adotou o slogan "O Rio Civiliza-se", evidenciando os projetos de modernizações e urbanizações da cidade, bem como as campanhas contra as principais doenças da época.

$\mathrm{Na}$ literatura, esse período histórico foi importante para a difusão de obras que abordavam as inseguranças que os avanços tecnológicos poderiam trazer para a vida das pessoas. No contexto nacional da época encontra-se a obra de Coelho Neto, que apesar de ser pouco conhecida, possui características do gênero especulativo e reflete uma sociedade influenciada pelas ideias europeias.

É notório que a obra de Coelho Neto dispõe de influências da obra Frankenstein (1818) da autora Mary Shelley - que se destacou no âmbito da FC. Assim, é possível verificar em $A$ 
Esfinge características de diferentes gêneros dentre os quais aqueles relacionados às narrativas especulativas.

\section{REFERÊNCIAS}

CANDIDO, Antônio. Literatura e Sociedade. 9.ED. Rio de Janeiro: Ouro sobre Azul. 2006.

CANDIDO, Antônio. A personagem do Romance. 11. ED. São Paulo: Perspectiva. 2007.

CARNEIRO, André. Introdução ao Estudo da Science Fiction. São Paulo. 1968.

CAUSO, Roberto de S. Ficção científica, fantasia e horror no Brasil - 1875 a 1950. Belo Horizonte: Editora UFMG, 2003.

COSTA, Luiz Antonio Severo da. O Brasil de 1900 a 1910. Rio de Janeiro: Biblioteca Nacional. 1980.

EWALD, Ariane P. Tecnologia e progresso: O Brasil civiliza-se no século XIX. Revista LOGOS: Comunicação e Universidade, v.6, n. 1, 2001.

GINWAY, M. Elizabeth. Ficção Científica Brasileira: Mitos Culturais e Nacionalidade no País do Futuro. São Paulo: Devir. 2005.

GINWAY, M. Transgendering in Luso-Brazilian Speculative Fictions from Machado de Assis to the present. Luso-Brazilian Review, v.47, n. 1, 2010.

NETO, Coelho. A Esphinge. Porto: Chardron, 1920.

NEVES, M. de S.: Os cenários da república. O Brasil na virada do século XIX para o século XX. In: DELGADO, Lucília de Almeida Neves e FERREIRA, Jorge Luís (Orgs.). Brasil Republicano: Estado, sociedade civil e cultura política. O tempo do liberalismo excludente. Da Proclamação da República à Revolução de 1930. 1a ed. Rio de Janeiro: Civilização Brasileira. 2003, v. 4.

SCHOLLHAMMER, Karl Erik. Ficção Brasileira Contemporânea. Rio de Janeiro. 2009

SEBASTIÃO, Sônia. Sujeito Pós-Moderno: do andrógino a pós-humano. Revista Comunicação \& Cultura, n 9 (1646-4877). 2010. 
SEVCENKO, Nicolau. Literatura como missão: tensões sociais e criação cultural na Primeira República. São Paulo: Brasiliense, 1999.

SILVA, Alexander M. O admirável mundo novo da República Velha: o nascimento da fícção científica brasileira no começo do século XX. Rio de Janeiro, 2008.

SILVA, Alexander M. República velha, decadente e colonial: configurações do gótico brasileiro finissecular. Rio de Janeiro: Dialogarts, 2015.

TAVARES, Bráulio. O que é Ficção Científica? São Paulo: Brasiliense. 1992. 